\title{
Aging of the Cerebral Cortex
}

\author{
Tak Pan Wong*, Ph.D.
}

\begin{abstract}
Significant structural trimming of neuronal structures in the cerebral cortex has long been considered as a primary cause of various age-related cortical dysfunctions. While recent findings provided additional data to support this notion, current understanding of cortical neuronal functions in aging also revealed the relationship of neuronal plasticity and imbalances between different neurotransmitter systems with the formation of age-related cortical dysfunctions. Manipulating these age-related alterations in neuronal function may be a novel therapeutic approach in the treatment of cortical dysfunctions in aging. This review will focus our current understanding of age-related changes in neuronal structures and functions in the cerebral cortex. Implication of these age-related alterations will be discussed.
\end{abstract}

The importance of the cerebral cortex in various motor and cognitive functions have drawn scientists' attention to the study of its age-related modifications in the last few decades. Although substantial structural and neurochemical changes in the aged cerebral cortex have been frequently reported, these changes displayed both temporal and regional specificity with age. In the following sections, critical findings regarding modifications in the aged cerebral cortex will be reviewed.

\section{STRUCTURAL CHANGES}

\section{Shrinkage of the aged cerebral cortex}

The most striking feature of aging brains is their shrinkage (1-3). The advent of magnetic resonance imaging (MRI) has provided an accurate non-invasive proof of cortical shrinkage with age (4). This agerelated shrinkage also coincides with the weight loss $(5,6)$ and expansion of the ventricular volume in the aged brain (7). For instance, human brains from individuals over 60 years old have been shown to be $17 \%$ lighter than brains of young adults (8).

\footnotetext{
* To whom correspondence should be addressed: Rm 3608, 2146 Health Sciences Mall, Department of Physiology, University of British Columbia, Vancouver, British Columbia, V6T 1 Z3.
}

It is important to note that this age-related shrinkage is region specific. For instance, Haug and coworkers (9) have shown that areas 7 and 17 (parietal and occipital cortex) exhibited no shrinkage in aged brains, while $>15 \%$ atrophy was found in areas 6 and 11 (extrapyramidal and orbital cortex).

\section{Neuronal loss}

Extensive neuronal loss in the aged brain has long been suggested to be the primary factor explaining age related neuronal shrinkage. Cortical neuronal loss in the aged brain was first reported by Brody's group (1). Further study of cell loss in the neocortex showed that primarily large neurons are lost during aging $(1,10,11)$, although loss of small neurons have also been reported $(8,12)$. Indeed, Meier-Ruge and coworkers (13) have hypothesized that 100,000 neurons in the human brain disappear daily resulting in a $19.7 \%$ reduction in cell number at the age of 80 .

The occurrence of extensive neuronal loss in aged brains was questioned by a finding from Haug and coworkers (14). Haug's group found that using the common method for tissue preparation, young cortical tissue actually shrinks more than old tissue in histological preparations. Since most studies of cell count had been based on cell density measurement, Haug's group raised the possibility that the number of 
neurons in young brains was overestimated. After correcting for shrinkage, Haug's group observed no neuronal loss but an increase in neuronal density after a decrease in brain volume in the aged neostriatum and cerebral cortex (15). An independent study from Terry and coworkers also supported no age-related cell loss in the cerebral cortex (11). Recent findings of no age-related loss of cortical neurons in both monkeys (16) and humans (17) further weaken the significance of neuronal loss with age (for review, see 18).

One of the major factors in causing the brain shrinkage with age is the loss of white matter. MRI studies have revealed significant loss of the white matter in aged brains $(19,20)$. In particular, Guttmann and coworkers reported that the loss of white matter is more serious than the loss of gray matter in the cerebral cortex from aged human subjects. Similar findings were obtained from Peters and coworkers using monkeys as their animal models (21). They also showed that the loss of white matter in the aged monkey neocortex correlated closely with their age-related cognitive decline. Damage of myelinated fibers with advancing age has been shown to be the prime factor causing the loss of white matter volume (22,23). Interestingly, oligodendrocytes, which are responsible for the formation of myelin in the brain, displayed various agerelated modifications, including swollen processes, inclusion of aging pigments in their cell bodies, and aggregation with other oligodendrocytes (24). These changes in oligodendrocyte may be related to the loss of myelinated fibers in aged brains. In summary, there is no conclusive evidence supporting a significant loss of neurons with age. Instead, loss of white matter could be an important factor in contributing to the overt brain shrinkage.

\section{Dendritic loss in aging}

Dendrites in the brain are important neuronal structures for synaptic contacts. They account for $90 \%$ of the total surface area of a neuron's receptive surface area $(25,26)$. Synapses make contacts on dendritic shafts and specialized dendritic structures called dendritic spines. Most synapses containing excitatory neurotransmitters like glutamate establish contacts on dendritic spines $(27,28)$. Significant agerelated loss of dendrites in the cerebral cortex has been first reported by Scheibel and coworkers (29). These age-related dendritic losses include both shortening (30,31)and fewer dendritic branches $(32,33)$. Losses in basal dendrites might have some regional specificity. For instance, more accentuated loss of basal dendrites was reported in the deeper cortical layer $\mathrm{V}$ when compared to superficial layers
II/III $(34,35)$. It is also important to note that dendritic losses in aged brains are not an inevitable process. For instance, no loss of dendrites in layer II pyramidal neurons has been reported in the entorhinal cortex of aged rats (36).

Loss of dendritic spines is another consistent change in aged pyramidal neurons. Spine loss on basal dendrites has been frequently reported (see 30,31). This loss is so prominent that up to $50 \%$ decrease in dendritic spines could be found, representing a much higher rate of loss than the mean of $10-20 \%$ loss of dendrites in the age brain $(37,38)$. Taken together, these studies provide evidence for a substantive loss of dendrites and dendritic surface of pyramidal neurons in aged brains. This significant loss of dendritic structures may limit the availability of postsynaptic substrate in aged brains for synaptic connections.

\section{Synaptic changes}

Synapses are the most important structures for neuronal communication. These structures link neurons inside the brain by directionally conveying neuronal information with different neurotransmitters. The importance of these structures in cognitive function has been recently addressed in the studies of synaptic loss in Alzheimer's disease (AD, see 39,40). Studies of synaptic loss during normal aging have been massively explored in the last two decades.

Quantitative studies using electron microscopy revealed significant loss of synapses with age in laboratory animals $(41,42)$ and humans $(43,44)$. This age-related structural change also displays regional specificity. For instance, in Wistar rats aged from 3 to 17 months, there was a $22 \%$ decrease in the synaptic density of the associative cortex, but only a $9 \%$ decrease in the motor-sensory cortex (45). In fact, some cortical regions, such as the piriform cortex, have been shown to be devoid of aged-induced decline (46). In addition, not every kind of synapse is altered equally with age. Adams's group has reported age-related loss of asymmetrical synapses, but not symmetrical synapses, in the layer I region of the somatosensory cortex in aged humans (43).

Apart from synaptic loss, age-related modification of synaptic structure has been reported. Adams and Jones (41) showed that terminals in the parietal cortex of aged rats contain fewer mitochondria, synaptic vesicles, reduced vacuolar and tubular cisternae, and displayed smaller presynaptic area. Fewer mitochondria were also observed in postsynaptic dendritic spines in the same study. The loss of these intracellular structures may compromise metabolism and function of synapses in the aged brain. However, loss of synapses and changes in presynaptic structure 
has been shown to be accompanied by an increase in the mean length of postsynaptic active zone (47). These structural modifications in the remaining synapses of the aged brain may represent a compensatory phenomenon to maintain normal cortical synaptic function.

In the cerebral cortex, the available evidence so far points to significant structural loss with age. They include disappearance of dendrites, dendritic spines, and synapses in the aged cerebral cortex. Since the number of neurons probably remains rather stable in the aged cerebral cortex, the loss of these pre- and postsynaptic structures would result in a substantial loss of interneuronal connections in the aged cerebral cortex. In the following section, I will summarize agerelated modification of two different neurotransmitters, which play important roles in neuronal communication.

\section{NEUROCHEMICAL CHANGES}

Age-related modification of different neurotransmitter systems in the cerebral cortex has been extensively documented. The present evidence would indicate that neurotransmitter systems are affected differentially by aging. For instance, studying the concentration of serotonin, norepinephrine, and dopamine in the cerebral cortex of rat brains at different developmental stages has shown that while serotonin concentration remains unchanged until very old aged (3 years), levels of norepinephrine and dopamine progressively decrease starting at 1 year of age (48). Thus, instead of resulting from a general decline in neurotransmission, the reduction of neuronal function in the aged brain is more likely caused by an imbalance between different neurotransmitter systems. The following passages will discuss the major excitatory and inhibitory neurotransmitters, which are glutamate and g-aminobutyric acid (GABA), respectively.

\section{Glutamate}

Glutamate is the most important amino acid in mediating excitatory synaptic transmission of the cerebral cortex $(49,50)$. Efferent fibers from the cerebral cortex to either extracortical or cortical regions utilize glutamate as a neurotransmitter $(51,52)$. Most glutamate immunoreactive neurons are pyramidal neurons. Since glutamate also plays important roles in cellular metabolism, its role as a neurotransmitter has been historically debated vigorously $(53,54)$; however, its role as a major neurotransmitter is widely accepted today. There are four major types of glutamate receptors $(55,56)$. N-methyl-D-aspartate (NMDA) receptors, aamino-3-hydroxy-5-methyl-4-isoxazole propionic acid
(AMPA) receptors, and kainate receptors belong to the family of ligand-gated ion channels. The last group of glutamate receptors is the $G$ protein-coupled metabotropic glutamate (mGluR) receptor.

The multiplicity of glutamate functions in the nervous system makes the presence of glutamate a poor indicator of glutamatergic synaptic function. Indeed, both decrease $(57,58)$ and no change $(59,60)$ in the basal glutamate level have been observed in aged rat brains. Studying the evoked release of glutamate also revealed conflicting results. For instance, using the same strength of electrical stimulation that elicited an increase in glutamate release in the prefrontal cortex of young rats failed to induce any change in glutamate release in the same cortical region from aged rats (61). However, glutamate release caused by high extracellular potassium, which induced depolarization of neurons, is actually higher in brain tissue from older rats (62).

By far the most consistent age-related change in the glutamatergic system is the loss of glutamate receptors. Significant decreases in the mRNA level of glutamate receptors were found in the aged cerebral cortex (63). Among different glutamate receptors, NMDA receptors are preferentially altered in the aged cerebral cortex. Decreases in NMDA binding was shown in the monkey's parietal and occipital cortex $(64,65)$. In rodents, decreases in the number of NMDA receptors with age has also been shown $(66,67)$.

Apart from a decrease in NMDA receptors in the aged cerebral cortex, studies of the change in different NMDA receptor subunits with age also displayed significant age-related modifications. For instance, mRNA level of both NR1 and NR2B subunits of the NMDA receptor have been shown to decrease preferentially in the aged cerebral cortex, whereas no age-related change was observed in the NR2A subunit (68). The modification of subunit expression may alter the receptor composition of NMDA receptor in the aged brain and lead to age-related changes in the binding properties of this receptor $(69,70)$ and/or physiological properties such as desensitization (71).

Various findings suggest that kainate and AMPA receptors may exhibit greater resistance to age-related change than NMDA receptors. Binding studies performed with homogenized cerebral cortex revealed significant decrease in NMDA but not AMPA and kainate receptors (72). This lack of change in the AMPA and kainate subtype may be due to several factors. First, the age-related change of AMPA and kainate receptors may be restricted to fewer cortical regions than the NMDA subtype (73). In addition, the loss of AMPA and kainate receptors may occur at a later time point of 
aging than NMDA receptors (74). Finally, the smaller decrease in AMPA receptor with age may be due to its plasticity towards age-related insults. For instance, separating the age cohort by their cognitive performance revealed an increased in the binding of AMPA receptors in the aged-impaired group (75). Although little has been done on the age-related change in metabotropic receptors binding, a decrease in the density of metabotropic receptors has also been reported in the frontal cortex (74). Taken together, these findings support a significant loss of postsynaptic glutamatergic receptors, especially the NMDA subtype, in the aged brain.

It is however important to note that a decrease in receptor density does not always give rise to lower excitatory synaptic function in the brain. For instance, while the density of NMDA receptor decreased in an accelerated senescence mice model, the level of glutamate and the amount of glutamate release in both the hippocampus and cerebral cortex was increased (76). In addition, decrease in NMDA receptor density has been shown to parallel by an increase in the affinity of these receptors in aged brain $(66,77)$. Whether these potential compensatory changes in receptor function could maintain a normal excitatory synaptic function in the aged cerebral cortex remains to be established.

\section{GABA}

GABA is the major inhibitory neurotransmitter in the cerebral cortex (78). This neurotransmitter is present mainly in intrinsic neurons $(79,80)$. Indeed, 10-15 percent of cortical neurons have been shown to be GABAergic (81). GABA receptors in the cerebral cortex can be separated into the GABAA and GABAB subtypes.

Decrease in GABAergic parameters with age has been frequently reported. For instance, the level of GABA in the cerebrospinal fluid from aged human is lower than in younger controls $(82,83)$. In the cerebral cortex, decrease in the GABA content with age has been reported in preparations using either synaptosomes (84) or microdissected tissues (58). GABA transport also decreases significantly with age (85). Finally, a decrease in GABAB receptor mediated postsynaptic current has been observed in the aged brain (86).

While there is evidence to support a decline in the level of GABA with age, no evidence supported a decrease in GABAergic neurons in the aged cerebral cortex $(87,88)$. Unlike glutamate receptors, binding studies revealed inconsistent alterations in the level of GABA receptors in the aged cerebral cortex. For instance, binding of GABAA receptors in aged brains is either lower than $(89,90)$ or similar to the level of that in young brains $(65,91)$. Interestingly, although significant decreases in the level of mRNA of different GABAA receptor subunits with age have been reported $(92,93)$, there was not an age-related change in protein expression of different GABAA receptor subunits (94). Finally, no change in the binding of allosteric ligands at GABAA receptors with age was observed. Studying the binding of benzodiazepine site at the GABAA receptors also revealed no change with age $(95,96)$. Binding of GABAB receptors also revealed little modification with age (97). These observations suggest that GABAergic receptors could be less vulnerable than glutamate receptors in aging.

Despite the lack of any modification in the binding of GABAA agonists and modulators, binding of the GABAA receptor-coupled ionophore in the cerebral cortex is decreased significantly in the aged brain $(91,92)$. A decrease in picrotoxin binding, which requires an open receptor/channel, was also observed in the aged cerebral cortex (98). These findings suggest that the kinetic/structural properties the GABAA receptors, instead of its density, are affected in aging. However, it is not clear whether these changes would result in a substantial decrease in the inhibitory neurotransmission in the aged cerebral cortex.

\section{FUNCTIONAL CHANGES}

Decreases in the functional capacity of the central nervous system with age occur universally in all living organisms. For instance, significant alteration in the gait control, sleeping cycle, and learning and memory with age are the three commonest neural impairments in aged humans (for review, see 99). While these functional alterations in aged brains may be related to the structural and neurochemical modifications I have summarized in the last few sections, mechanisms underlying these age-related deficits are still largely unknown. The formation of complex behavioral responses relies on an even more complicate activation and inactivation of different group of neurons, whose activities are in turn determined by countless synaptic inputs. Age-related modification of cortical activities from systemic to synaptic levels will be discussed.

\section{Systemic level}

Knowing that performing certain cognitive or sensorimotor task can evoke reproducible brain activities in particular cortical area, alteration in the response pattern with age can be an indication of the 
age-related functional modification of the studied cortical area. Using electroencephalography (EEG), which reveals electrical activities from a group of cortical neurons or a cortical area, cortical brain potentials evoked by performing memory tasks have been shown to be diminished and delayed in the elderly $(100,101)$. Brain potentials in response to sensory inputs also have a longer delay in aged subjects $(102,103)$. Measurements of EEG in rodents also revealed significant decreases in amplitude $(104,105)$ and a delay in the appearance of evoked brain potential (106). Apart from a decline in evoked cortical activities, alteration of the pattern of brain potentials can also be found in the aged cerebral cortex (107).

Using functional magnetic resonance imaging (fMRI) also revealed a positive correlation between the reduction in cortical activation and cognitive performance. For instance, decrease in cortical activities in aged people has been matched with the decline in working memory formation (108). Comparing the activation of cortical tissue upon auditory stimulation also revealed significant agerelated decreases (109). Thus, results from these noninvasive recording techniques support a decline in evoked cortical activity with age.

\section{Cellular level}

Studies of spontaneous activities of cortical neurons found significant decrease in the firing rate $(110,111)$. In addition to single unit recordings, measurement of activity from multiple neurons simultaneously in the parietal cortex also revealed significant decrease in discharge rate in aged rats (112). However, a decrease in neuronal firing rate is not necessarily a universal phenomenon of aging. Lack of age-related change in spontaneous neuronal firing rate has also been reported $(113,114)$. The inconsistency in age-related changes in neuronal firing rates may be due to the methodology used in these studies. Alternatively, loss of spontaneous neuronal activities may be restricted to specific brain areas only. In addition, factors which determine the firing of a neuron, including the threshold for the action potential, strength of excitatory and inhibitory synaptic inputs, can be differentially affected in aging (for a review, see (115)). Thus, understanding the change in these cellular and synaptic parameters with age may provide important information to the modification of neuronal firing in the aged cerebral cortex.

Apart from decreases in firing rate, modification of neuronal firing pattern with age may play important roles in age-related deficits. For instance, neurons in the suprachiasmatic nuclei from aged rats displayed aberrant firing patterns, which may be the basis for the decline in circadian rhythms with age (116). However, no evidence so far shows a similar modification of cortical neuronal firing pattern with age.

\section{Synaptic level}

While the loss of synaptic structures with age is a widely accepted modification in the aging cerebral cortex, little is known about the functional significance of this structural loss in the cerebral cortex. Most of our current understanding of age-related changes in synaptic function stems from studies of the hippocampus.

In the CA1 region, significant loss of synapses in the CA1 area have been shown to match with a decrease in evoked synaptic potential (117). Loss of evoked monosynaptic GABAB-mediated synaptic potential IPSPs has also been observed in the CA1 area $(86,118)$. However, compensatory changes to maintain the magnitude of synaptic potential have also been reported. For instance, studying the modification of perforant path - dentate granule cell synapses in aged rats showed a significant reduction in the maximal field excitatory synaptic potential in aged rats, which is matched with the loss of synaptic terminals in this area. However, for a given magnitude of stimulation, a larger synaptic potential was obtained in aged rats, suggesting that the strength of remaining synapses in aged rats are in fact higher $(119,120)$. Indeed, compensatory changes in the CA1 area of aged rats have also been reported. For instance, the NMDA receptors mediated EPSP has been shown to increase in the aged CA1 region (121). These compensatory alterations in synaptic function may explain a relatively slight or minimal age-related functional change concomitant with a substantial structural loss in aged brains (122).

Another well-known modification of synaptic function in the aged hippocampus is the reduced capability in the formation of long term potentiation (LTP). Repeatedly stimulated afferent fibers have been shown to induce an enduring increase in synaptic transmission, which has been regarded as a cellular mechanism of learning and memory (123). Both activation of NMDA receptors and nitric oxide have been shown to be important in the LTP induction (for review, see (124)). In aged rats, the threshold for the induction of LTP is increased $(125,126)$, and the decay of LTP is accelerated $(127,128)$.

\section{Plasticity}

Significant plastic changes in aged brain have been widely reported. In the presence of substantial synaptic loss, both an increase in the number of dendrites (129) or enlargement of remaining synaptic boutons (130) have been shown in aged tissues. Interestingly, the topographic organization of sensory inputs in the 
somatosensory cortex is modified with age (131). In addition, performing the same cognitive function can activate different cortical structures in young and aged brains (132)). Since topographic rearrangement of sensory inputs in the cerebral cortex can be induced after damages of sensory afferents (for review, see $133,134)$, the topographic changes in aged brain may be the consequence of age-related structural loss in the aged cerebral cortex.

Although aged cerebral cortex still displayed a certain degree of neuronal plasticity, various evidences point to a reduced tolerance of the aged cerebral cortex towards lesion or detrimental influence. For instance, stress induced increase in glutamate release is five times higher than the level found in younger animals (135). This increase in extracellular levels of excitatory neurotransmitters could result in damage of neuronal tissues in the aged brain (for review, see (136). Lesion studies also revealed similar decline in plasticity of the aged cerebral cortex. Lesions of the cerebral cortex after hypoxic insults are more severe in old rats than in younger controls (137). While lesion of the nucleus basalis magnocellularis caused an upregulation of GABA receptors in the frontal cortex of young rats, no modification of GABA receptors was observed in aged rats (138). Indeed, the structural and functional changes in the aged cerebral cortex discussed above may limit the available resource for coping with insults.

\section{CONCLUSION}

While the majority of studies in the literature regard age-related reduction in cortical synaptic structures as the primary substrates of age-related decline in learning and memory, the characteristics of these age-related structural losses also shed light for possible manipulation of the loss of cortical functions in aging. Firstly, reduction of synaptic structures in aged cerebral cortex displays regional and temporal specificity. For instance, glutamatergic and GABAergic have been shown to exhibit different extent of modification in aging. The imbalance between these neurotransmitter systems may have a more direct impact to cortical functions than solely a morphological trimming of synaptic structures in aged brains. Interestingly, we have shown that the ratios of spontaneous glutamatergic and GABAergic synaptic event in normally aged and aged impaired rats are different (139). Restoring the imbalance between different neurotransmitters in aging may be a novel therapeutic approach in treating agerelated cortical dysfunction. In addition, while aged brains exhibited compromised neuronal plasticity, aged brains still possess remarkable compensatory capability. For example, we have showed that while pyramidal neurons in aged brain receive fewer synaptic inputs than young rats, frequency of spontaneous synaptic inputs between young and aged rats are similar (140). These compensatory potential in aged brain may be another therapeutic targets for correcting aged-related functional deficits, which in turn not only will benefit the life quality of the aged population, but also will reduce the financial burden of treating aged related dysfunctions in our society.

\section{REFERENCES}

1. Brody H. Organization of the cerebral cortex, III, A study of aging in the human cerebral cortex. Journal of Comparative Neurology. 1955;102:511-556.

2. Dekaban AS. Changes in brain weights during the span of human life: relation of brain weights to body heights and body weights. Annals of Neurology. 1978;4:345-356.

3. Matsumae M, Kikinis R, Morocz IA et al. Age-related changes in intracranial compartment volumes in normal adults assessed by magnetic resonance imaging. Journal of Neurosurgery. 1996;84:982-991.

4. Raz N, Briggs SD, Marks W, Acker JD. Age-related deficits in generation and manipulation of mental images: II. The role of dorsolateral prefrontal cortex. Psychology and Aging. 1999; 14:436-444.

5. Ho KC, Roessmann U, Straumfjord JV, Monroe G. Analysis of brain weight. I. Adult brain weight in relation to sex, race, and age. Archives of pathology and laboratory medicine. 1980;104:635-639.

6. Haug H. The aging human cerebral cortex: Morphometry of areal differences and their functional meaning. In: Dani SU, Hori A, Walter GF, eds. Principles of neural aging. Amsterdam: Elsevier Science; 1997:247-261.

7. Foundas AL, Zipin D, Browning CA. Age-related changes of the insular cortex and lateral ventricles: conventional MRI volumetric measures. Journal of Neuroimaging. 1998;8:216221.

8. DeKosky ST, Bass NH. Effects of aging and senile dementia on the microchemical athology of human cerebral cortex. In: Amaducci L, Davison AN, Antuono P, eds. Aging. New York: Raven Press; 1980:33-37.

9. Haug H, Barmwater U, Eggers R, Fischer D, Kuhel S, Sass NL. Anatomical changes in aging brain: morphometric analysis of the human presencephalon. In: Cervos-Navarro J, Sarkander HI, eds. Aging. New York: Raven Press; 1983:1-12.

10. Henderson G, Tomlinson BE, Gibson PH. Cell counts in human cerebral cortex in normal adults throughout life using an image analysing computer. Journal of the Neurological Sciences. 1980;46:113-136.

11. Terry RD, Deteresa R, Hansen LA. Neocortical cell counts in normal human adult aging. Annals of Neurology. 1987;21:530539.

12. Brody H. Aging of the vertebrate brain. In: Rockstein M, Sussman HM, eds. Development and aging in the nervous system. New York: Academic Press; 1973:121-133.

13. Meier-Ruge $\mathrm{W}$, Hunziker O, Iwangoff $\mathrm{P}$, Reichlmleter $\mathrm{K}$, Sandoz P. Alteration of morphological and neurochemical parameters of the brain due to normal aging. In: Nandy K, ed. 
Senile dementia: Biochemical approach. New York: ElsevierNorth Holland; 1978:33-44.

14. Haug H, Knebel G, Mecke E, Orun C, Sass NL. The aging of cortical cytoarchitectonics in the light of stereological investigations. Progress in Clinical and Biological Research. 1981;59B:193-197.

15. Haug H, Eggers R. Morphometry of the human cortex cerebri and corpus striatum during aging. Neurobiology of Aging. 1991;12:336-338

16. Peters A. The absence of significant neuronal loss from cerebral cortex with age. Neurobiology of Aging. 1993;14:657-658.

17. Gómez-Isla T, Price JL, McKeel DW, Jr., Morris JC, Growdon JH, Hyman BT. Profound loss of layer II entorhinal cortex neurons occurs in very mild Alzheimer's disease. Journal of Neuroscience. 1996;16:4491-4500.

18. Wickelgren I. For the cortex, neuron loss may be less than thought. Science. 1996;273:48-50.

19. Guttmann CR, Jolesz FA, Kikinis R et al. White matter changes with normal aging. Neurology. 1998;50:972-978.

20. Gunning-Dixon FM, Raz N. The cognitive correlates of white matter abnormalities in normal aging: a quantitative review. Neuropsychology. 2000;14:224-232.

21. Peters A, Moss MB, Sethares C. Effects of aging on myelinated nerve fibers in monkey primary visual cortex. Journal of Comparative Neurology. 2000;419:364-376.

22. Feldman ML, Peters A. Ballooning of myelin sheaths in normally aged macaques. Journal of Neurocytology. 1998;27:605-614.

23. Lintl P, Braak H. Loss of intracortical myelinated fibers: a distinctive age-related alteration in the human striate area. Acta Neuropathologica (Berl). 1983;61:178-182.

24. Peters A. Age-related changes in oligodendrocytes in monkey cerebral cortex. Journal of Comparative Neurology. 1996;371:153-163.

25. Mungai JM. Dendritic patterns in the somatic sensory cortex of the cat. Journal of Anatomy. 1967;101:403-418.

26. Sholl DA. The surface area of cortical neurons. Journal of Anatomy. 1955;89:571-572.

27. White EL. Cortical Circuits: Synaptic Organization of the Cerebral Cortex Structure, Function, and Theory. Boston: Birkhauser; 1989.

28. De Felipe J, Farinas I. The pyramidal neuron of the cerebral cortex: morphological and chemical characteristics of the synaptic inputs. Progress in Neurobiology. 1992;39:563-607.

29. Scheibel ME, Lindsay RD, Tomiyasu U, Scheibel AB. Progressive dendritic changes in aging human cortex. Experimental Neurology. 1975;47:392-403.

30. Mervis R. Structural alterations in neurons of aged canine neocortex: a Golgi study. Experimental Neurology. 1978;62:417-432.

31. Anderson B, Rutledge V. Age and hemisphere effects on dendritic structure. Brain. 1996;119:1983-1990.

32. Vaughan DW. Age-related deterioration of pyramidal cell basal dendrites in rat auditory cortex. Journal of Comparative Neurology. 1977;171:501-515.

33. Jacobs B, Scheibel AB. A quantitative dendritic analysis of Wernicke's area in humans. I. Lifespan changes. Journal of Comparative Neurology. 1993;327:83-96.

34. de Brabander JM, Kramers RJ, Uylings HB. Layer-specific dendritic regression of pyramidal cells with ageing in the human prefrontal cortex. European Journal of Neuroscience. 1998;10:1261-1269.

35. Nakamura S, Akiguchi I, Kameyama M, Mizuno N. Age-related changes of pyramidal cell basal dendrites in layers III and V of human motor cortex: a quantitative Golgi study. Acta Neuropathologica. 1985;65:281-284.
36. Coleman PD, Flood DG. Net dendritic stability of layer II pyramidal neurons in F344 rat entorhinal cortex from 12 to 37 months. Neurobiology of Aging. 1991;12:535-541.

37. Leuba G. Aging of dendrites in the cerebral cortex of the mouse. Neuropathology and Applied Neurobiology. 1983;9:467-475.

38. Jacobs B, Driscoll L, Schall M. Life-span dendritic and spine changes in areas 10 and 18 of human cortex: a quantitative Golgi study. Journal of Comparative Neurology. 1997;386:661-680.

39. Terry RD, Masliah E, Salmon DP et al. Physical basis of cognitive alterations in Alzheimer's disease: synapse loss is the major correlate of cognitive impairment. Annals of Neurology. 1991;30:572-580.

40. DeKosky ST, Scheff SW. Synapse loss in frontal cortex biopsies in Alzheimer's disease: correlation with cognitive severity. Annals of Neurology. 1990;27:457-464.

41. Adams I, Jones DG. Quantitative ultrastructural changes in rat cortical synapses during early-, mid- and late-adulthood. Brain Research. 1982;239:349-363.

42. Zecevic N, Bourgeois JP, Rakic P. Changes in synaptic density in motor cortex of rhesus monkey during fetal and postnatal life. Developmental Brain Research. 1989;50:11-32.

43. Adams I. Comparison of synaptic changes in the precentral and postcentral cerebral cortex of aging humans: a quantitative ultrastructural study. Neurobiology of Aging. 1987;8:203-212.

44. Huttenlocher PR. Synaptic density in human frontal cortex developmental changes and effects of aging. Brain Research. 1979;163:195-205.

45. Markus EJ, Petit TL. Neocortical synaptogenesis, aging, and behavior: lifespan development in the motor-sensory system of the rat. Experimental Neurology. 1987;96:262-278.

46. Curcio CA, McNelly NA, Hinds JW. Aging in the rat olfactory system: relative stability of piriform cortex contrasts with changes in olfactory bulb and olfactory epithelium. Journal of Comparative Neurology. 1985;235:519-528.

47. Adams I. Plasticity of the synaptic contact zone following loss of synapses in the cerebral cortex of aging humans. Brain Research. 1987;424:343-351.

48. Timiras PS, Hudson DB, Oklund S. Changes in central nervous system free amino acids with development and aging. Progress in Brain Research. 1973;40:267-275.

49. Krnjevic K, Phillis JW. Acetylcholine-sensitive cells in the cerebral cortex. Journal of Physiology. 1963;166:296-327.

50. Jasper H, Khan R, Elliot K. Amino acids released from the cerebral cortex in relation to its state of activation. Science. 1965;147:1448-1449.

51. Baughman RW, Gilbert CD. Aspartate and glutamate as possible neurotransmitters in the visual cortex. Journal of Neuroscience. 1981:1:427-439

52. Peinado JM, Mora F. Glutamic acid as a putative transmitter of the interhemispheric corticocortical connections in the rat. Journal of Neurochemistry. 1986;47:1598-1603.

53. Krnjevic K. Chemical Nature of Synaptic Transmission in Vertebrates. Physiological Reviews. 1974;54:418-540.

54. Streit P. Glutamate and aspartate as transmitter candidates for systems of the cerebral cortex. In: Peters A, Jones EG, eds. Cerebral Cortex. New York and London: Plenum Press; 1984:119-143.

55. Seeburg PH. The TiPS/TINS lecture: the molecular biology of mammalian glutamate receptor channels. Trends in Pharmacological Sciences. 1993;14:297-303.

56. Hollmann M, Heinemann S. Cloned glutamate receptors. Annual Review of Neuroscience. 1994;17:31-108.

57. Dawson R, Jr., Wallace DR, Meldrum MJ. Endogenous glutamate release from frontal cortex of adult and aged rats. Neurobiology of Aging. 1989;10:665-668.

58. Banay-Schwartz M, Lajtha A, Palkovits M. Changes with aging 
in the levels of amino acids in rat CNS structural elements. I. Glutamate and related amino acids. Neurochemical Research. 1989; 14:555-562.

59. Cobo M, Exposito I, Porras A, Mora F. Release of amino acid neurotransmitters in different cortical areas of conscious adult and aged rats. Neurobiology of Aging. 1992;13:705-709.

60. Kornhuber ME, Kornhuber J, Retz W, Riederer P. L-glutamate and L-aspartate concentrations in the developing and aging human putamen tissue. Journal of Neural Transmission General Section. 1993;93:145-150.

61. Cobo M, Exposito I, Mora F. Aging, prefrontal cortex, and amino acid neurotransmitters: differential effects produced by electrical stimulation. Neurobiology of Aging. 1993;14:187190.

62. Saransaari P, Oja SS. Age-related changes in the uptake and release of glutamate and aspartate in the mouse brain. Mechanisms of Ageing and Development. 1995;81:61-71.

63. Carpenter MK, Parker I, Miledi R. Messenger RNAs coding for receptors and channels in the cerebral cortex of adult and aged rats. Molecular Brain Research. 1992;13:1-5.

64. Wenk GL, Pierce DJ, Struble RG, Price DL, Cork LC. Agerelated changes in multiple neurotransmitter systems in the monkey brain. Neurobiology of Aging. 1989;10:11-19.

65. Wenk GL, Walker LC, Price DL, Cork LC. Loss of NMDA, but not GABAA, binding in the brains of aged rats and monkeys. Neurobiology of Aging. 1991;12:93-98.

66. Cohen SA, Muller WE. Age-related alterations of NMDAreceptor properties in the mouse forebrain: partial restoration by chronic phosphatidylserine treatment. Brain Research. 1992;584:174-180.

67. Kito S, Miyoshi R, Nomoto $\mathrm{T}$. Influence of age on NMDA receptor complex in rat brain studied by in vitro autoradiography. Journal of Histochemistry and Cytochemistry. 1990;38:1725-1731

68. Magnusson KR. Declines in mRNA expression of different subunits may account for differential effects of aging on agonist and antagonist binding to the NMDA receptor. Journal of Neuroscience. 2000;20:1666-1674

69. Priestley T, Laughton P, Myers J, Le Bourdelles B, Kerby J, Whiting PJ. Pharmacological properties of recombinant human N-methyl-D-aspartate receptors comprising NR1a/NR2A and NR1a/NR2B subunit assemblies expressed in permanently transfected mouse fibroblast cells. Molecular Pharmacology. 1995;48:841-848.

70. Gallagher MJ, Huang H, Pritchett DB, Lynch DR. Interactions between ifenprodil and the NR2B subunit of the N-methyl-Daspartate receptor. Journal of Biological Chemistry. 1996;271:9603-9611.

71. Monyer H, Sprengel R, Schoepfer R et al. Heteromeric NMDA receptors: molecular and functional distinction of subtypes. Science. 1992;256:1217-1221.

72. Tamaru M, Yoneda Y, Ogita K, Shimizu J, Nagata Y. Agerelated decreases of the N-methyl-D-aspartate receptor complex in the rat cerebral cortex and hippocampus. Brain Research. 1991;542:83-90

73. Magnusson KR, Cotman CW. Age-related changes in excitatory amino acid receptors in two mouse strains. Neurobiology of Aging. 1993;14:197-206.

74. Magnusson KR. Aging of glutamate receptors: correlations between binding and spatial memory performance in mice Mechanisms of Ageing and Development. 1998;104:227-248.

75. Le Jeune H, Cecyre D, Rowe W, Meaney MJ, Quirion R. Ionotropic glutamate receptor subtypes in the aged memoryimpaired and unimpaired Long-Evans rat. Neuroscience. 1996;74:349-363.
76. Kitamura Y, Zhao XH, Ohnuki T, Takei M, Nomura Y. Agerelated changes in transmitter glutamate and NMDA receptor/channels in the brain of senescence-accelerated mouse. Neuroscience Letters. 1992;137:169-172.

77. Peterson C, Cotman CW. Strain-dependent decrease in glutamate binding to the N-methyl-D-aspartic acid receptor during aging. Neuroscience Letters. 1989;104:309-313.

78. Krnjevic K. Role of GABA in cerebral cortex. Canadian Journal of Physiology and Pharmacology. 1997;75:439-451.

79. Meinecke DL, Peters A. GABA immunoreactive neurons in rat visual cortex. Journal of Comparative Neurology. 1987;261:388-404.

80. Ribak CE. Aspinous and sparsely-spinous stellate neurons in the visual cortex of rats contain glutamic acid decarboxylase. Journal of Neurocytology. 1978;7:461-478

81. Penny GR, Afsharpour S, Kitai ST. The glutamate decarboxylase-, leucine enkephalin-, methionine enkephalinand substance P-immunoreactive neurons in the neostriatum of the rat and cat: evidence for partial population overlap. Neuroscience. 1986;17:1011-1045.

82. Tohgi H, Takahashi S, Abe T. The effect of age on concentrations of monoamines, amino acids, and their related substances in the cerebrospinal fluid. Journal of Neural Transmission - Parkinsons Disease and Dementia Section. 1993;5:215-226.

83. Hare TA, Wood JH, Manyam BV, Gerner RH, Ballenger JC, Post RM. Central nervous system gamma-aminobutyric acid activity in man. Relationship to age and sex as reflected in CSF. Archives of Neurology. 1982;39:247-249.

84. Wheeler DD, Ondo JG. Endogenous GABA concentration in cortical synaptosomes from young and aged rats. Experimental Gerontology. 1986;21:79-85.

85. Wheeler DD. Aging of membrane transport mechanisms in the central nervous system. GABA transport in rat cortical synaptosomes. Experimental Gerontology. 1982;17:71-85.

86. Krzywkowski P, Potier B, Billard JM, Dutar P, Lamour Y. Synaptic mechanisms and calcium binding proteins in the aged rat brain. Life Sciences. 1996;59:421-428.

87. Mountjoy CQ, Rossor MN, Iversen LL, Roth M. Correlation of cortical cholinergic and GABA deficits with quantitative neuropathological findings in senile dementia. Brain. 1984;107:507-518.

88. Rossor MN, Garrett NJ, Johnson AL, Mountjoy CQ, Roth M, Iversen LL. A post-mortem study of the cholinergic and GABA systems in senile dementia. Brain. 1982;105:313-330.

89. Govoni S, Memo M, Saiani L, Spano PF, Trabucchi M. Impairment of brain neurotransmitter receptors in aged rats. Mechanisms of Ageing and Development. 1980;12:39-46.

90. Nabeshima T, Yamada K, Hayashi $\mathrm{T}$ et al. Changes in muscarinic cholinergic, PCP, GABAA, D1, and 5-HT2A receptor binding, but not in benzodiazepine receptor binding in the brains of aged rats. Life Sciences. 1994;55:1585-1593.

91. Erdö SL, Wolff JR. Age-related loss of t[35S]butylbicyclophosphorothionate binding to the gammaaminobutyric acidA receptor-coupled chloride ionophore in rat cerebral cortex. Journal of Neurochemistry. 1989;53:648-651.

92. Mhatre MC, Ticku MK. Aging related alterations in GABAA receptor subunit mRNA levels in Fischer rats. Molecular Brain Research. 1992;14:71-78.

93. Gutierrez A, Khan ZU, Miralles CP, De Blas AL. Altered expression of gamma $2 \mathrm{~L}$ and gamma $2 \mathrm{~S}$ GABAA receptor subunits in the aging rat brain. Molecular Brain Research 1996;35:91-102.

94. Gutierrez A, Khan ZU, Miralles CP et al. GABAA receptor subunit expression changes in the rat cerebellum and cerebral 
cortex during aging. Molecular Brain Research. 1997;45:59-70.

95. Ruano D, Machado A, Vitorica J. Absence of modifications of the pharmacological properties of the GABAA receptor complex during aging, as assessed in 3- and 24-month-old rat cerebral cortex. European Journal of Pharmacology. 1993;246:81-87.

96. Tsang CC, Speeg KV, Jr., Wilkinson GR. Aging and benzodiazepine binding in the rat cerebral cortex. Life Sciences. 1982;30:343-346.

97. Turgeon SM, Albin RL. GABAB binding sites in early adult and aging rat brain. Neurobiology of Aging. 1994;15:705-711.

98. Mhatre MC, Fernandes G, Ticku MK. Aging reduces the mRNA of alpha 1 GABAA receptor subunit in rat cerebral cortex. European Journal of Pharmacology. 1991;208:171-174.

99. Timiras PS. Aging of the nervous system: functional changes. In: Timiras PS, ed. Physiological basis of aging and geriatrics. Florida: CRC Press, Inc.; 1994:103-114.

100. Joyce CA, Paller KA, McIsaac HK, Kutas M. Memory changes with normal aging: behavioral and electrophysiological measures. Psychophysiology. 1998;35:669-678.

101. Nielsen-Bohlman L, Knight RT. Prefrontal alterations during memory processing in aging. Cerebral Cortex. 1995;5:541-549.

102. Liu FJ, Wu X, Yu MX. ERPs of characters of Chinese words compared with tone and picture stimuli in adolescents and aged persons. Clinical Electroencephalography. 1998;29:146-152.

103. Shaw NA, Cant BR. Age-dependent changes in the latency of the pattern visual evoked potential. Electroencephalography and Clinical Neurophysiology. 1980;48:237-241.

104. Valjakka A, Sirvio J, Pitkanen A, Riekkinen PJ. Brain amines and neocortical EEG in young and aged rats. Comparative Biochemistry and Physiology Part C, Pharmacology, Toxicology and Endocrinology. 1990;96:299-304.

105. Buzsaki G, Bickford RG, Armstrong DM et al. Electric activity in the neocortex of freely moving young and aged rats. Neuroscience. 1988;26:735-744.

106. Simpson DM, Erwin CW. Evoked potential latency change with age suggests differential aging of primary somatosensory cortex. Neurobiology of Aging. 1983;4:59-63.

107. Trott CT, Friedman D, Ritter W, Fabiani M. Item and source memory: differential age effects revealed by event-related potentials. Neuroreport. 1997;8:3373-3378.

108. Rypma B, D'Esposito M. Isolating the neural mechanisms of age-related changes in human working memory. Nature Neuroscience. 2000;3:509-515.

109. Yousem DM, Maldjian JA, Hummel T et al. The effect of age on odor-stimulated functional MR imaging. AJNR American Journal of Neuroradiology. 1999;20:600-608.

110. Stern WC, Pugh WW, Morgane PJ. Single unit activity in frontal cortex and caudate nucleus of young and old rats. Neurobiology of Aging. 1985;6:245-248.

111. Roy D, Singh R. Age-related change in the multiple unit activity of the rat brain parietal cortex and the effect of centrophenoxine. Experimental Gerontology. 1988;23:161-174.

112. Sharma D, Singh R. Age-related decline in multiple unit action potentials of cerebral cortex correlates with the number of lipofuscin-containing neurons. Indian Journal of Experimental Biology. 1996;34:776-781.

113. Palombi PS, Caspary DM. Physiology of the aged Fischer 344 rat inferior colliculus: responses to contralateral monaural stimuli. Journal of Neurophysiology. 1996;76:3114-3125.

114. Mizumori SJ, Barnes CA, McNaughton BL. Differential effects of age on subpopulations of hippocampal theta cells. Neurobiology of Aging. 1992;13:673-679.

115. Barnes CA. Normal aging: regionally specific changes in hippocampal synaptic transmission. Trends in Neurosciences. 1994;17:13-18.
116. Satinoff E, Li H, Tcheng TK et al. Do the suprachiasmatic nuclei oscillate in old rats as they do in young ones? American Journal of Physiology. 1993;265:R1216-R1222.

117. Barnes CA, Rao G, Foster TC, McNaughton BL. Regionspecific age effects on AMPA sensitivity: electrophysiological evidence for loss of synaptic contacts in hippocampal field CA1. Hippocampus. 1992;2:457-468.

118. Potier B, Rascol O, Jazat F, Lamour Y, Dutar P. Alterations in the properties of hippocampal pyramidal neurons in the aged rat. Neuroscience. 1992;48:793-806.

119. Foster TC, Barnes CA, Rao G, McNaughton BL. Increase in perforant path quantal size in aged F-344 rats. Neurobiology of Aging. 1991;12:441-448.

120. Barnes CA, McNaughton BL. Physiological compensation for loss of afferent synapses in rat hippocampal granule cells during senescence. Journal of Physiology. 1980;309:473-485.

121. Jouvenceau A, Dutar P, Billard JM. Alteration of NMDA receptor-mediated synaptic responses in CA1 area of the aged rat hippocampus: contribution of GABAergic and cholinergic deficits. Hippocampus. 1998;8:627-637.

122. Johnson SC, Saykin AJ, Baxter LC et al. The relationship between fMRI activation and cerebral atrophy: comparison of normal aging and alzheimer disease. Neuroimage. 2000;11:179187

123. Bliss TV, Lomo T. Long-lasting potentiation of synaptic transmission in the dentate area of the anaesthetized rabbit following stimulation of the perforant path. Journal of Physiology. 1973;232:331-356.

124. Zorumski CF, Izumi Y. Modulation of LTP induction by NMDA receptor activation and nitric oxide release. Progress in Brain Research. 1998;118:173-182.

125. Deupree DL, Bradley J, Turner DA. Age-related alterations in potentiation in the CA1 region in F344 rats. Neurobiology of Aging. 1993;14:249-258.

126. Rosenzweig ES, Rao G, McNaughton BL, Barnes CA. Role of temporal summation in age-related long-term potentiationinduction deficits. Hippocampus. 1997;7:549-558.

127. Detoledo-Morrell L, Geinisman Y, Morrell F. Agedependent alterations in hippocampal synaptic plasticity: relation to memory disorders. Neurobiology of Aging. 1988;9:581-590.

128. Sharp PE, Barnes CA, McNaughton BL. Effects of aging on environmental modulation of hippocampal evoked responses. Behavioral Neuroscience. 1987;101:170-178.

129. Buell SJ, Coleman PD. Dendritic growth in the aged human brain and failure of growth in senile dementia. Science. 1979;206:854-856.

130. Bertoni-Freddari C, Giuli C, Pieri C, Paci D. Age-related morphological rearrangements of synaptic junctions in the rat cerebellum and hippocampus. Archives of Gerontology and Geriatrics. 1986;5:297-304.

131. Spengler F, Godde B, Dinse HR. Effects of ageing on topographic organization of somatosensory cortex. Neuroreport. 1995;6:469-473

132. Grady CL. Brain imaging and age-related changes in cognition. Experimental Gerontology. 1998;33:661-673.

133. Kaas JH, Merzenich MM, Killackey HP. The reorganization of somatosensory cortex following peripheral nerve damage in adult and developing mammals. Annual Review of Neuroscience. 1983;6:325-356

134. Diamond ME, Armstrong-James M, Ebner FF. Experiencedependent plasticity in adult rat barrel cortex. Proceedings of the National Academy of Sciences of the United States of America. 1993;90:2082-2086.

135. Lowy MT, Wittenberg L, Yamamoto BK. Effect of acute stress 
on hippocampal glutamate levels and spectrin proteolysis in young and aged rats. Journal of Neurochemistry. 1995;65:268274.

136. Dirnagl U, Iadecola C, Moskowitz MA. Pathobiology of ischaemic stroke: an integrated view. Trends in Neurosciences. 1999;22:391-397.

137. Hoyer S, Krier C. Ischemia and aging brain. Studies on glucose and energy metabolism in rat cerebral cortex. Neurobiology of Aging. 1986;7:23-29.

138. Wellman CL, Pelleymounter MA. Differential effects of nucleus basalis lesions in young adult and aging rats. Neurobiology of Aging. 1999;20:381-393.

139. Wong, T. P., Cuello, A. C., and De Koninck, Y. Imbalance of tonic excitation and inhibition onto layer $\mathrm{V}$ pyramidal neurons in aged impaired rats. Abstracts Society for Neuroscience 26, 1838. 2000.

140. Wong TP, Marchese G, Casu MA, Ribeiro-da-Silva A, Cuello AC, De Koninck Y. Loss of presynaptic and postsynaptic structures is accompanied by compensatory increase in action potentialdependent synaptic input to layer $\mathrm{V}$ neocortical pyramidal neurons in aged rats. Journal of Neuroscience. 2000;20:8596-8606.

Tak Pan Wong received his B.Sc. in Biology and M.Phil. in Physiology from University of Hong Kong (Hong Kong, PRC). He has recently finished his Ph.D., which focused on the cortical synaptic modification in aging at McGill University (Montréal, Québec, Canada). During his Ph.D. study, he received awards from the Croucher Foundation (Hong Kong), FRSQ-FCAR-Santé, and the Alzheimer Society of Canada. Dr. Wong has been recently awarded a post-doctoral fellowship from NSERC for commencing his research training in the Brain Research Centre, University of British Columbia, Canada. 